\title{
POTENTIAL CONSEQUENCES OF "DIRTY" ARCTIC SEA ICE
}

\section{(Abstract)}

\author{
by
}

Stephanie Pfirman,

(GEOMAR/Christian Albrechts University, Wischhofstrasse 1-3, Bldg. 4, D-2300 Kiel 14 , Federal Republic of Germany)

Manfred A. Lange,

(Alfred-Wegener Institute for Polar and Marine Research, Postfach 120161-Columbusstrasse, D-2850 Bremerhaven, Federal Republic of Germany)

and

Tamara S. Ledley

(Department of Space Physics and Astronomy and the Earth Systems Institute, Rice University, P.O. Box 1892, Houston, TX 77251, U.S.A.)

Observations of high particulate loads on Eurasian Basin sea ice in 1987 raise questions of consequence for sediment budgets, ice melting, ice modeling and remote sensing. Biogenic and lithogenic particles were observed in concentrations high enough to color the ice surface brown over large area (greater than $15 \times 15 \mathrm{~km}^{2}$ ) within the Siberian branch of the Transpolar Drift stream. The sediment is most likely incorporated when ice forms on the Siberian shelf seas, and is concentrated at the ice surface after several years of summer surface melting and biological growth within the Arctic basin. Much of the particle-laden multi-year ice appears to leave the Arctic basin via Fram Strait, depositing its sediment load along the axis of the East Greenland Current.
To date, variation in sea-ice particle load has not been taken into consideration when modeling ice thickness or distribution for past or future environmental scenarios, with the exception of soot deposited from nuclear war. Naturally elevated surface-particle concentration may occur if there is increased deposition from long-range or coastal transport of aeolian material, increased sediment input into sea ice which is then exposed to surface melting, and/or increased biogenic productivity on the ice surface. Such conditions may have prevailed during the Younger Dryas. If particle loads become high enough to cause extensive sea-ice melting, changes may be expected in sea-ice concentration and distribution, sea-floor sedimentation rates, and oceanic productivity.

\section{CHANGES IN GLACIER LENGTH INDUCED BY CLIMATE CHANGES}

\section{(Abstract)}

by

\author{
C.F. Raymond, E.D. Waddington, and Tómas Jøhannesson
}

(Geophysics Program AK-50, University of Washington, Seattle, WA 98195, U.S.A.)

Time scales for adjustment in the length of a glacier to changing climate may be described in terms of a relatively short time scale, $\tau_{\mathrm{S}}$ and a longer memory time, $\tau_{\mathrm{m}}$. The memory $\tau_{\mathrm{m}}$ represents the time scale needed for asymptotic approach of the glacier to a steady state following a climate change event. $\tau_{\mathrm{m}}$ is determined by simple continuity considerations concerning the total volume change that must occur to reach steady state and the balance rate that drives the change. We show that $\tau_{\mathrm{m}}$ is relatively independent of the size of the climate change or to details of how ice flow is related to the geometry of the glacier. The time scale $\tau_{s}$ represents the time between a climate event and the occurrence of substantial changes in the glacier length. We show that, in contrast to $\tau_{\mathrm{m}}, \tau_{\mathrm{s}}$ is highly dependent on the size of the climate change and on details of ice dynamics. This dependence is investigated by several ice-flow models including a simple one in which ice transport is determined by local thickness and slope, as in the analysis of kinematic waves, and a finite element representation that fully includes longitudinal stress gradients. The ice-flow models are subjected to massbalance perturbations of varying size - from small, for which linearization approximations are valid, to large, for which linearization breaks down.

The following behavior may be identified. Increasing the size of a mass-balance rate change causes a more rapid initial response of a glacier terminus, which tends to shorten $\tau_{\mathrm{S}}$. Longitudinal stress gradients damp local variations in velocity and thereby slow the propagation and diffusion of kinematic waves and retard the response of the terminus, which tends to lengthen $\tau_{s}$. Longitudinal stress gradients transmit forces to the terminus region and influence the terminus motion without the necessity of redistributing mass from the glacier length into the terminus zone, which tends to shorten $\tau_{\mathrm{s}}$. These various results indicate that accurate modeling of the short term responses of glaciers to climate change requires fairly sophisticated ice-flow models. However, for purposes of tracking glacier lengths (or areas) over time scales considerably great than $\tau_{S}$, fairly simple ice-flow models may suffice. 